\title{
Assessing genetic potential in germplasm collections of crop plants by marker-trait association: a case study for potatoes with quantitative variation of resistance to late blight and maturity type
}

\author{
Christiane Gebhardt ${ }^{1, *}$, Agim Ballvora ${ }^{1}$, Birgit Walkemeier ${ }^{1}$, Petra Oberhagemann ${ }^{1}$ and \\ Konrad Schüler ${ }^{2}$ \\ ${ }^{1}$ Max-Planck-Institute for Plant Breeding Research, Carl von Linné Weg 10, 50829 Cologne, Germany; \\ ${ }^{2} I P K$ Gatersleben, Genbank Außenstelle Nord, 18190 Groß Lüsewitz, Germany; *Author for correspondence \\ (phone: ++49 (0)221 5062 430; fax: ++49 (0)221 5062 413; e-mail: gebhardt@mpiz-koeln.mpg.de)
}

Received 24 December 2002; accepted in revised form 29 August 2003

Key words: Association mapping, QTL, Late blight, Maturity, Potato

\begin{abstract}
Genetic diversity of crop plants resulting from breeding and selection is preserved in gene banks. Utilization of such materials for further crop improvement depends on knowledge of agronomic performance and useful traits, which is usually obtained by phenotypic evaluation. Associations between DNA markers and agronomic characters in collections of crop plants would (i) allow assessment of the genetic potential of specific genotypes prior to phenotypic evaluation, (ii) identify superior trait alleles in germplasm collections, (iii) facilitate high resolution QTL mapping and (iv) validate candidate genes responsible for quantitative agronomic characters. The feasibility of association mapping was tested in a gene bank collection of 600 potato cultivars bred between 1850 and 1990 in different countries. The cultivars were genotyped with five DNA markers linked to previously mapped QTL for resistance to late blight and plant maturity. Specific DNA fragments were tested for association with these quantitative characters based on passport evaluation data. Highly significant association with QTL for resistance to late blight and plant maturity was detected with PCR markers specific for $R 1$, a major gene for resistance to late blight, and anonymous PCR markers flanking the $R l$ locus at 0.2 Centimorgan genetic distance. The marker alleles associated with increased resistance and later plant maturity were traced to an introgression from the wild species $S$. demissum. These DNA markers are the first marker that are diagnostic for quantitative agronomic characters in a large collection of cultivars.
\end{abstract}

\section{Introduction}

Since the domestication of crop plants from wild species twelve thousand years ago (Salamini et al. 2002) human societies have selected from genetically diverse plant populations those individuals that were better adapted to their needs. About hundred years ago, Mendelian and quantitative genetics provided the scientific basis for modern pedigree-based plant breeding. Since then, the genetic diversity of crops was broadened by the introgression of genes for re- sistance to biotic and abiotic stress from related wild species. Biodiversity generated by the breeding process is preserved in gene bank collections of cultivars and breeding lines. Such collections represent populations of genotypes that are related by descent but with admixture of genome segments of related species. Germplasm collections are not natural populations resulting from random mating. On the other hand, they are not truly experimental either as they result from various breeding processes. 
In human populations, association studies are considered as a feasible strategy for the elucidation of the molecular basis of complex inherited diseases. The association between a molecular haplotype and disease phenotype will allow genetic risk assessment and, eventually, personalized therapy (Schafer and Hawkins 1998; Risch 2000). Similarly, the association between DNA haplotypes and complex agronomic characters may allow the assessment of genetic potential in collections of varieties, breeding lines and wild species that are related by descent. Haplotypes associated with agronomic performance will provide excellent diagnostic tools for marker-assisted breeding and facilitate identification and molecular cloning of genes controlling complex agronomic characters.

Whether and to what extent association exists between quantitative trait loci (QTL) and linked DNA markers in historical collections of cultivars and breeding lines is difficult to estimate based on theoretical assumptions (Hanson 1959; Xiong and Guo 1997). In maize, a first example of association between DNA polymorphisms at a candidate gene locus and a QTL for flowering time has been demonstrated in a population of inbred lines of common descent (Thornsburry et al. 2001). The potato (Solanum tuberosum ssp tuberosum) is a non-inbred, tetraploid crop showing tetrasomic inheritance. Potato varieties are bred by crossing heterozygous parents and selecting among the F1 progeny. Heterozygous genotypes are immediately fixed due to vegetative propagation via tubers. The genetic basis of the crop was broadened over the last hundred years by introgressions of genes for resistance to biotic and abiotic stress from other tuber bearing Solanum species (Ross 1986). The first introgressions originated from the wild hexaploid species Solanum demissum, which is highly resistant to late blight, the most devastating disease of potato that is caused by the oomycete Phytophthora infestans (Ross 1986; Kamoun 2001). In a gene bank collection of potato cultivars representing the genetic diversity of more than hundred years of breeding and selection, we tested whether association would be detectable between variety descriptors for quantitative agronomic characters and DNA-based markers known to be linked to QTL for these characters.

The quantitative characters studied were maturity type and resistance of foliage and tubers to late blight. Maturity type is a complex character that controls the plant's life span from sprouting of the tuber to flowering, tuber formation, maturation and senescence.
Variation of time to maturity is the consequence of various degrees of adaptation of short day S. tuberosum to the long days of middle and Northern Europe (Steineck 1956). Under long day conditions, field resistance to late blight and plant maturity are correlated traits. Late maturing cultivars are, on average, more resistant to late blight (Ross 1986). Cultivars are selected and grouped according to maturity type, with earliness being the preferred character. Scores for late blight resistance and maturity type are important parameters of variety passport data (http:// www.genres.de/eva/kartoffel.htm). QTL for late blight resistance of foliage and tubers and maturity type have been identified and mapped in experimental populations of diploid potatoes (Leonards-Schippers et al. 1994; Oberhagemann et al. 1999; Collins et al. 1999; Visker et al. 2003). Major QTL for both late blight resistance and plant maturity are located on potato chromsome $\mathrm{V}$ in a hot spot for resistance to pathogens that also contains $R 1$, a major gene for resistance to late blight (Leonards-Schippers et al. 1992; Ballvora et al. 2002; Gebhardt and Valkonen 2001). PCR-based markers tightly linked to this resistance hot spot were used in a first association study in a vegetatively propagated crop.

\section{Materials and methods}

Plant material. Six hundred potato cultivars maintained at the IPK Genbank Außenstelle Nord, 18190 Groß Lüsewitz, Germany (Angeli et al. 2000), were used. Varieties and lines are listed in alphabetical order, including country and date of origin, in supplementary Table 1 (http://www.mpiz-koeln.mpg.de/ $\sim$ gebhardt/potasso.html). Most varieties originated from middle and eastern European countries, some from Northern and Southern Europe, North and South America and Asia. The oldest variety was "Tannenzapfen" from Germany (1850), the latest was Zhukowskiy ranniy from Russia (1993). Between one and eight accessions of 29 wild and cultivated Solanum species were obtained from the collection of the Bundesforschungsanstalt für Landwirtschaft (FAL, Braunschweig, Germany, courtesy of J. R. Hoekstra). Part of this material has been described previously in Debener et al. (1990). Three accessions of $S$. demissum were provided by the IPK Gatersleben, Genbank Außenstelle Nord (Groß Lüsewitz, Germany, courtesy of M. Geibel). Species and accession numbers are listed in the supplementary Table 2 
Table 1. PCR primers specific for the five markers tested for association with late blight resistance and plant maturity.

\begin{tabular}{lllll}
\hline Marker & Forward primer, 5' to 3' & Reverse Primer, 5' to 3' & $\mathrm{T}_{\mathrm{A}}$ & Reference \\
\hline BA47f2 & Taaccaacattatcttcttgcc & gaatttggagaggggtttgctg & 55 & This paper \\
R1 & cactcgtgacatatcctcacta & caaccetggcatgccacg & 55 & Ballvora et al. 2002 \\
CosA & ctcattcaaaatcagtttgatc & gaatgttgaatcttttgtgaagg & 55 & This paper \\
GP179 & ggtttagtgattgtgctgc & aatttcagacgagtaggcact & 55 & Meksem et al. 1995 \\
GP76 & atgaagcaacactgatgcaa & ttctccaatgaacgcaaact & 52 Oberhagemann et al. 1999 \\
\hline
\end{tabular}

Table 2. PCR fragment location, size and observed frequency.

\begin{tabular}{llcll}
\hline Marker fragment & Chromosome location & Fragment size $(\mathrm{bp})$ & Observed frequency & No of plants scored \\
\hline BA47f2 650 & V & 650 & 0.27 & 595 \\
R1 1400 & V & 1400 & 0.33 & 540 \\
R $1800_{\text {CosA }}$ unknown & V & 1800 & 0.57 & 512 \\
GP179 $_{570}$ & V & 210 & 0.31 & 585 \\
GP76 $_{500}$ & VI & 570 & 0.52 & 579 \\
\hline
\end{tabular}

(http://www.mpiz-koeln.mpg.de/ gebhardt/potasso.html). S. dulcamara was collected locally.

DNA extraction. DNA of the 600 cultivars was extracted from $20-50 \mathrm{mg}$ freeze dried leaf tissue per genotype in racks with $1.4 \mathrm{~mL}$ extraction tubes arranged in the 96-well format (Matrix Technologies, 61273 Wehrheim, Germany). Two $3.5 \mathrm{~mm}$ tungsten beads (Qiagen, 40724 Hilden, Germany) were added to each tube. Freeze dried leaves were ground to a fine powder with a Retsch Mixer Mill MM300 (Qiagen, 40724 Hilden, Germany). Total genomic DNA was extracted using P1 and P2 buffers of the E.Z.N.A. Plant DNA Minikit (Peqlab, 91052 Erlangen, Germany) according to the supplier's instructions. After precipitation with isopropanol and washing with $70 \%$ ethanol, the DNA pellets were dissolved in $50 \mu \mathrm{L}$ TE buffer, incubated for $30 \mathrm{~min}$ at $65^{\circ} \mathrm{C}$ and stored at $-20{ }^{\circ} \mathrm{C}$. CsCl-gradient purified DNA of the Solanum species, stored at $-20^{\circ} \mathrm{C}$, was available from earlier restriction fragment length polymorphism studies (Debener et al. 1990, and unpublished results of this laboratory).

Phenotypic values. Scores for resistance of foliage and tubers to late blight and for plant maturity were compiled from variety passport data (http://www.genres.de/eva/kartoffel.htm) and are included in supplementary Table 1 . Resistance scores ranged from 1 to 9, where 1 was highly susceptible and 9 was highly resistant. Scores for maturity were between 1 (very late maturing) and 9 (very early maturing).

Genotyping. Five markers were selected based on linkage to QTL for resistance to late blight and plant maturity (Oberhagemann et al. 1999; Collins et al. 1999). Markers BA47f2, CosA, and GP179, and the $R 1$ gene for resistance to late blight (Leonards-Schippers et al. 1992; Meksem et al. 1995; Ballvora et al. 2002) are located within $1 \mathrm{cM}$ on potato chromosome $\mathrm{V}$ (Figure 1) in a "hot spot" for pathogen resistance (Gebhardt and Valkonen 2001). Marker GP76 maps to potato chromosome VI (Oberhagemann et al. 1999). Cultivars and Solanum species were genotyped based on presence or absence of PCR fragments of specific size. Primer sequences are listed in Table 1. PCR was performed in $15 \mu \mathrm{L}$ buffer (Invitrogen Life Technologies, Karlsruhe, Germany), 0.2 mM dNTPs, $2.7 \mathrm{mM} \mathrm{MgCl} 2,0.7 \mu \mathrm{M}$ of each primer, $50 \mathrm{ng}$ template DNA and 1 unit Taq polymerase (Invitrogen). PCR conditions were: Initial denaturation for 1-2 min at $93{ }^{\circ} \mathrm{C}, 35-40$ cycles of $45 \mathrm{sec}$ at $93{ }^{\circ} \mathrm{C}, 45 \mathrm{sec}$ at the respective annealing temperature (Table 1) and 90 sec at $72{ }^{\circ} \mathrm{C}$, and one cycle of final extension for 10 min at $72{ }^{\circ} \mathrm{C}$. PCR products and restriction fragments were size separated by standard agarose gel electrophoresis and visualized by ethidium bromide staining. Primers for markers GP179 and CosA each generated one polymorphic fragment of 570 and 210 base pairs, respectively, in addition to monomorphic fragments of approx. 500 and 250 base pairs, respectively (Figure 1, lanes A and B). The 650 base pairs PCR product of marker BA47f2 was either present or absent (Figure 1, lanes C). Primers for the $R l$ resistance gene generated, besides the main product of $1400 \mathrm{bp}$ corresponding to the $R l$ resistance gene (Ballvora et al. 2002), several minor products of different sizes. One 

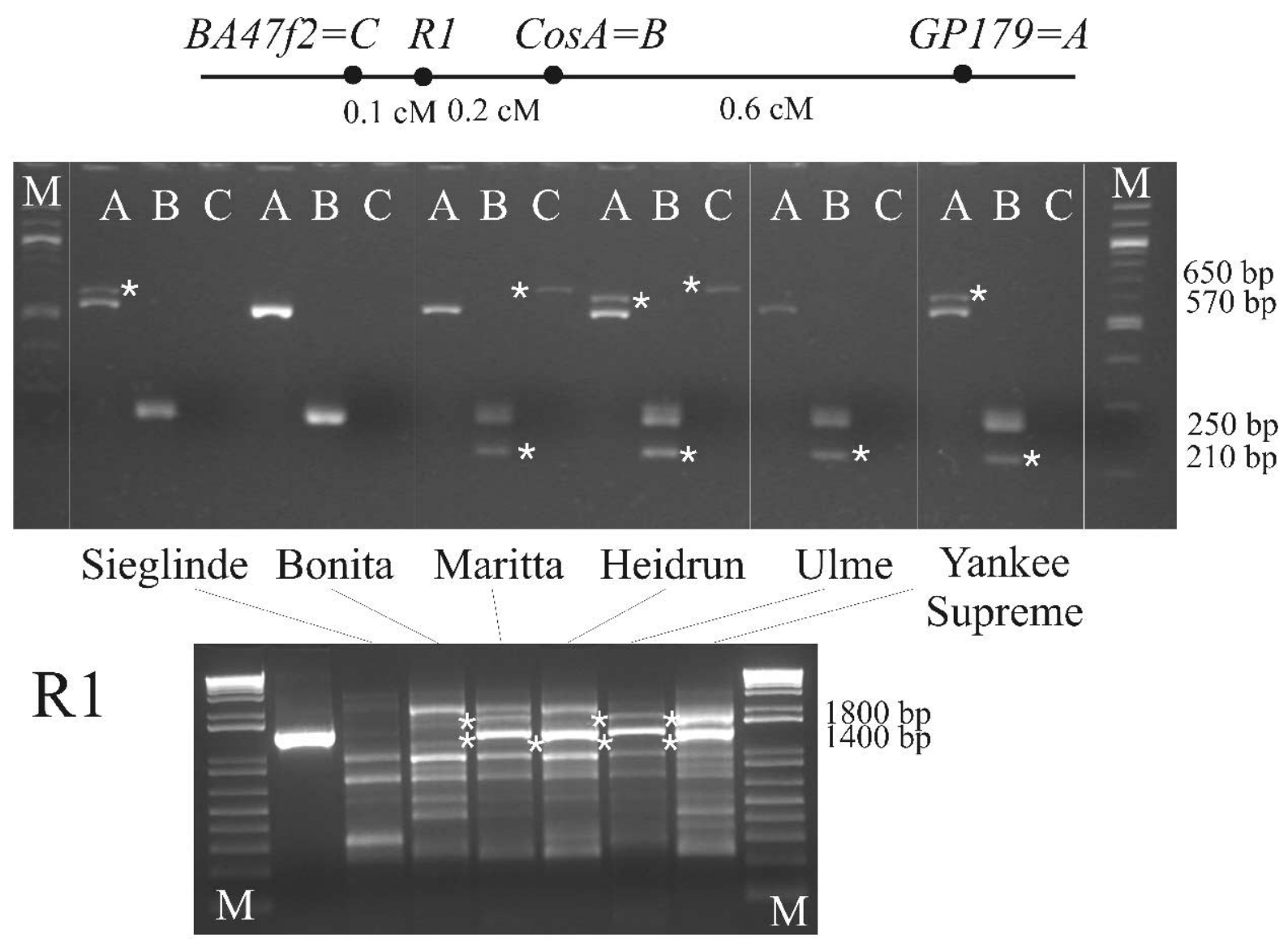

\section{BA \\ $87 \mathrm{~d} 17$}

Figure 1. PCR patterns of markers GP179, CosA, BA47f2 and R1 observed in the collection of 600 tetraploid potato cultivars. Patterns of the six varieties Sieglinde (Germany 1935), Bonita (Germany 1989), Maritta (Germany 1946), Heidrun (Germany 1978), Ulme (Germany 1991) and Yankee Supreme (USA 1983) are shown. Order and genetic distance between the marker loci on potato chromosome V are shown at the top of the Figure. The genetic distance of $0.1 \mathrm{cM}$ between loci $B A 47 f 2$ and $R 1$ corresponds to a physical distance of circa $300 \mathrm{~kb}$ (Ballvora et al. 2002). PCR products were amplified from genomic DNA using the specific primers listed in Table 1 and separated on standard agarose gel (4\% for GP179, CosA and BA47f2, $2 \%$ for R1). The marker fragments scored are indicated by *. BA87d17 = amplicon of the BAC clone containing the $R 1$ resistance gene (Ballvora et al. 2002). M = size marker. Sizes of PCR fragments are shown on the right.

of those minor products, a fragment of approx. 1800 base pairs, was scored in addition to the major 1400 bp fragment (Figure 1). GP76 was assayed as CAPS marker (cleaved amplified polymorphic sequence). Restriction of the amplification product with $R s a \mathrm{I}$ generated fragments of 600, 500 and 150 base pairs (shown in Oberhagemann et al. 1999) of which the $500 \mathrm{bp}$ fragment was scored.

Statistical analysis. Marker fragments were scored as present (1) or absent (0). Fragments that could not be scored reliably were declared as missing values ("2" in supplementary Table 1). Similarity of marker distribution in the collection was calculated by distance analysis between binary variables (simple similarity) using SPSS® software (München, Germany). Marker genotype classes were tested for association with phenotypic scores with the non-parametric Mann-Whitney-U test using the SPSS ${ }^{\circledR}$ software (München, Germany). The null hypothesis of no association was rejected at $P<0,05$.

\section{Results}

Pedigree structure. Six hundred of circa 1600 tetraploid potato cultivars (Angeli et al. 2000) maintained 


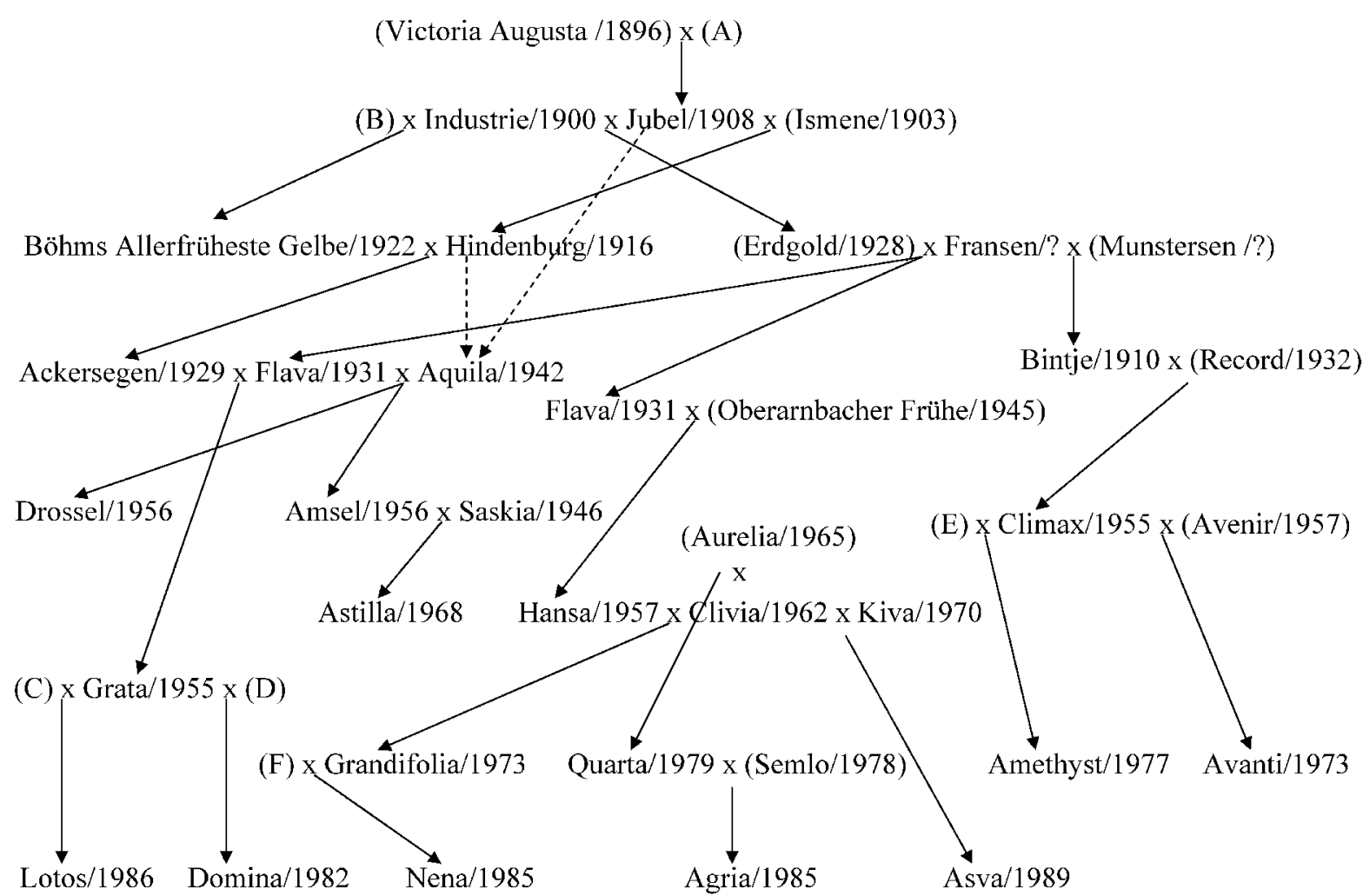

Figure 2. Pedigree structure of a subset of the varieties used for association mapping. The parents of the varieties were derived from Angeli et al. (2000) and Swiezynski et al. (1997). Varieties are shown with the year of registration. Parents in parenthesis were not included in the collection tested for association. Parents A, B, C, D, E and F were breeding clones not registered as varieties (detailed names in Swiezynski et al. 1997). The oldest varieties are separated from the latest ones by five to six meiotic generations.

at the gene bank Groß Lüsewitz were genotyped. According to pedigree information in Swiezynski et al. (1997) and Angeli et al. (2000), a single parent of 152 varieties was present in the collection of 600 genotypes. Both parents of 22 additional varieties were also included in the collection. In total, thirty nine percent of the genotypes were separated from each other by not more than one meiotic generation. A typical example of pedigree relationships (Figure 2) shows that 100 years of potato breeding correspond to five or six meiotic generations.

Genotypic analysis. Using sequence specific primers for five different markers (Table 1), DNA fragments were amplified by PCR from genomic DNA of the 600 cultivars. Representative examples of the observed PCR patterns are shown in Figure 1. The CosA primers generated, with one exception (cv Temp), a fragment of approx. 250 base pairs (Figure 1) in all cultivars tested and was used as DNA quality control. The score of all genotypes for six polymorphic DNA fragments is shown in supplementary
Table 3. Similarity between the distribution of PCR fragments in the cultivar collection.

\begin{tabular}{llllll}
\hline & $\mathrm{R}_{1400}$ & $\mathrm{R} 1_{1800}$ & $\mathrm{CosA}_{210}$ & $\mathrm{GP179}$ & $\mathrm{GP76}_{500}$ \\
\hline BA47f2 & 0.94 & 0.01 & 0.96 & 0.06 & 0.30 \\
$\mathrm{R}_{1400}$ & & 0.03 & 1.00 & 0.00 & 0.26 \\
$\mathrm{R}_{1800}$ & & & 0.02 & 0.20 & 0.05 \\
CosA $_{210}$ & & & & 0.02 & 0.26 \\
GP179 $_{570}$ & & & & & 0.08 \\
\hline
\end{tabular}

Table 1. The frequencies of the PCR fragments are shown in Table 2. The allele frequency is expected to be higher than the observed fragment frequency due to the unknown allele dosage in tetraploid genotypes that varies between 1 (simplex) and 4 (quadruplex). The PCR fragments BA47f $2_{650}, \mathrm{R} 1_{1400}$ and $\operatorname{Cos} \mathrm{A}_{210}$, located within $0.3 \mathrm{cM}$ on chromosome V (Figure 1), were similarly distributed in the cultivar collection (Table 3). The remaining fragments GP179 ${ }_{570}, \mathrm{R} 1_{1800}$ and $\mathrm{GP} 76_{500}$ were not correlated with these three fragments and did not correlate among themselves 
Table 4. Association test between marker classes and phenotypic scores for resistance to late blight of foliage and tubers (higher score indicates higher resistance) and for plant maturity (higher score indicates earlier maturity).

\begin{tabular}{|c|c|c|c|c|c|c|c|c|}
\hline \multirow[t]{2}{*}{ Marker fragment } & \multirow[t]{2}{*}{ Marker class } & \multirow[t]{2}{*}{ No of genotypes } & \multicolumn{2}{|c|}{ Foliage resistance } & \multicolumn{2}{|c|}{ Tuber resistance } & \multicolumn{2}{|l|}{ Plant maturity } \\
\hline & & & Mean (s. d.) & $\mathrm{P}$ & Mean (s. d.) & $\mathrm{P}$ & Mean (s. d.) & $\mathrm{P}$ \\
\hline \multirow[t]{2}{*}{ BA47f $2_{650}$} & 1 & 118 & $5.50(1.57)$ & 0.009 & $5.87(1.54)$ & 0.018 & $4.06(1.74)$ & 0.235 \\
\hline & 0 & 297 & $5.00(1.68)$ & & $5.46(1.74)$ & & $4.33(1.95)$ & \\
\hline \multirow{2}{*}{$\mathrm{R} 1_{1400}$} & 1 & 135 & $5.60(1.57)$ & 0.000 & $6.00(1.53)$ & 0.000 & $3.92(1.72)$ & 0.018 \\
\hline & 0 & 280 & $4.92(1.67)$ & & $5.37(1.74)$ & & $4.42(1.96)$ & \\
\hline \multirow[t]{2}{*}{$\mathrm{R} 1_{1800}$} & 1 & 224 & $4.97(1.68)$ & 0.002 & $5.39(1.80)$ & 0.003 & $4.04(1.80)$ & 0.079 \\
\hline & 0 & 164 & $5.51(1.57)$ & & $5.96(1.42)$ & & $4.42(1.98)$ & \\
\hline \multirow[t]{2}{*}{$\operatorname{Cos} \mathrm{A}_{210}$} & 1 & 134 & $5.60(1.57)$ & 0.000 & $6.02(1.53)$ & 0.000 & $3.94(1.73)$ & 0.026 \\
\hline & 0 & 281 & $4.93(1.67)$ & & $5.36(1.73)$ & & $4.41(1.95)$ & \\
\hline \multirow[t]{2}{*}{ GP179 570} & 1 & 219 & $5.13(1.64)$ & 0.896 & $5.58(1.70)$ & 0.991 & $4.26(1.79)$ & 0.803 \\
\hline & 0 & 196 & $5,16(1.70)$ & & 5.57 (1.69) & & $4.26(2.01)$ & \\
\hline \multirow[t]{2}{*}{$\mathrm{GP76}_{500}$} & 1 & 109 & $5.00(1.71)$ & 0.509 & $5.27(176)$ & 0.047 & $4.60(1.91)$ & 0.028 \\
\hline & 0 & 271 & $5.14(1.70)$ & & $5.66(1.71)$ & & $4.14(1.89)$ & \\
\hline
\end{tabular}

(Table 3). Fragment GP179 570 is tightly linked to the CosA, R1 and BA47f2 markers whereas marker GP76 $_{500}$ maps to a different chromosome. The map position of fragment $\mathrm{R} 1_{1800}$ is not known. It may be linked in repulsion phase to the $R 1$ locus on chromosome $\mathrm{V}$ or may be located on a different chromosome. This is supported by the observation that $\mathrm{R} 1_{1800}$ did not amplify from BAC clone BA87d17 containing the R1 gene (Figure 1).

Association test. Phenotypic passport data were available for a subset of the 600 potato genotypes. Four hundred and fifteen genotypes were selected for the association test, where evaluation data were available for resistance of foliage and tubers to late blight and for plant maturity (indicated by light blue background in supplementary Table 1). The same 415 genotypes were fully scored for the linked marker fragments BA47f $2_{650}, \mathrm{R} 1_{1400}, \operatorname{Cos} \mathrm{A}_{210}$ and GP179 570 on chromosome V. Some scores of fragments R $1_{1800}$ and $\mathrm{GP} 76_{500}$ were missing. The six marker fragments were tested for association with each trait using the non-parametric Mann-Whitney-U test (Table 4).

GP179 570 that was linked to QTL for all three traits when tested in experimental populations (Oberhagemann et al. 1999), was not significantly associated with any of these traits in the cultivar collection. In contrast, marker fragments BA47f $2_{650}, \mathrm{R} 1_{1400}, \mathrm{R} 1_{1800}$ and $\operatorname{Cos} \mathrm{A}_{210}$ were highly significantly associated with resistance of foliage and tubers to late blight. Presence of the marker fragments BA47f $2_{650}, \mathrm{R} 1_{1400}$ and $\operatorname{Cos} \mathrm{A}_{210}$ was associated with increased resistance of both foliage and tubers, whereas presence of $\mathrm{R} 1_{1800}$ was associated with increased susceptibility of foli- age and tubers. Moreover, $\mathrm{R} 1_{1400}$ and $\operatorname{Cos} \mathrm{A}_{210}$, but not BA47f $2_{650}$ and $\mathrm{R} 1_{1800}$, were significantly associated with maturity type. Later maturity was associated with presence of the fragment. Figure 3 shows the frequency distribution of cultivars having or not having the $\mathrm{R} 1_{1400}$ fragment, for the scores from 1 to 9 for resistance of foliage and tubers to late blight and for maturity type. Sixty three percent of the cultivars having the $\mathrm{R} 1_{1400}$ fragment were in the above average resistance categories 6 to 9 for foliage resistance, versus $40 \%$ that lacked $\mathrm{R} 1_{1400}$ (Figure $3 \mathrm{~A}$ ). Similarly for tuber resistance, $68 \%$ of the cultivars having $\mathrm{R} 1_{1400}$ scored between 6 and 9, compared to $48 \%$ lacking $\mathrm{R} 1_{1400}$ (Figure $3 \mathrm{~B}$ ). Only $11 \%$ of early and very early maturing cultivars (scores 6 to 9) had $\mathrm{R} 1_{1400}$, compared to $28 \%$ of the cultivars without $\mathrm{R} 1_{1400}$ (Figure 3C).

Marker fragment GP76 ${ }_{500}$ that tags a different QTL on potato chromosome VI was weakly associated with tuber resistance and maturity type, presence of the fragment being associated with increased resistance and later maturity (Table 4).

Introgression from $\mathrm{S}$. demissum. Genomic DNA of 114 accessions of 30 Solanum species including four accessions of $S$. demissum (supplementary Table 2), was evaluated for chromosome V markers BA47f2, R1, CosA and GP179. Similar to the potato cultivars, the $\operatorname{Cos} \mathrm{A}_{250}$ fragment was detected in all Solanum species tested, whereas the $\operatorname{Cos} \mathrm{A}_{210}$ fragment was present only in $S$. dulcamara, one single accession of $S$. microdontum and in all four accessions of $S$. demissum (Figure 4). Fragment $\mathrm{R} 1_{1400}$ was present in three of the four $S$. demissum accessions and in one 


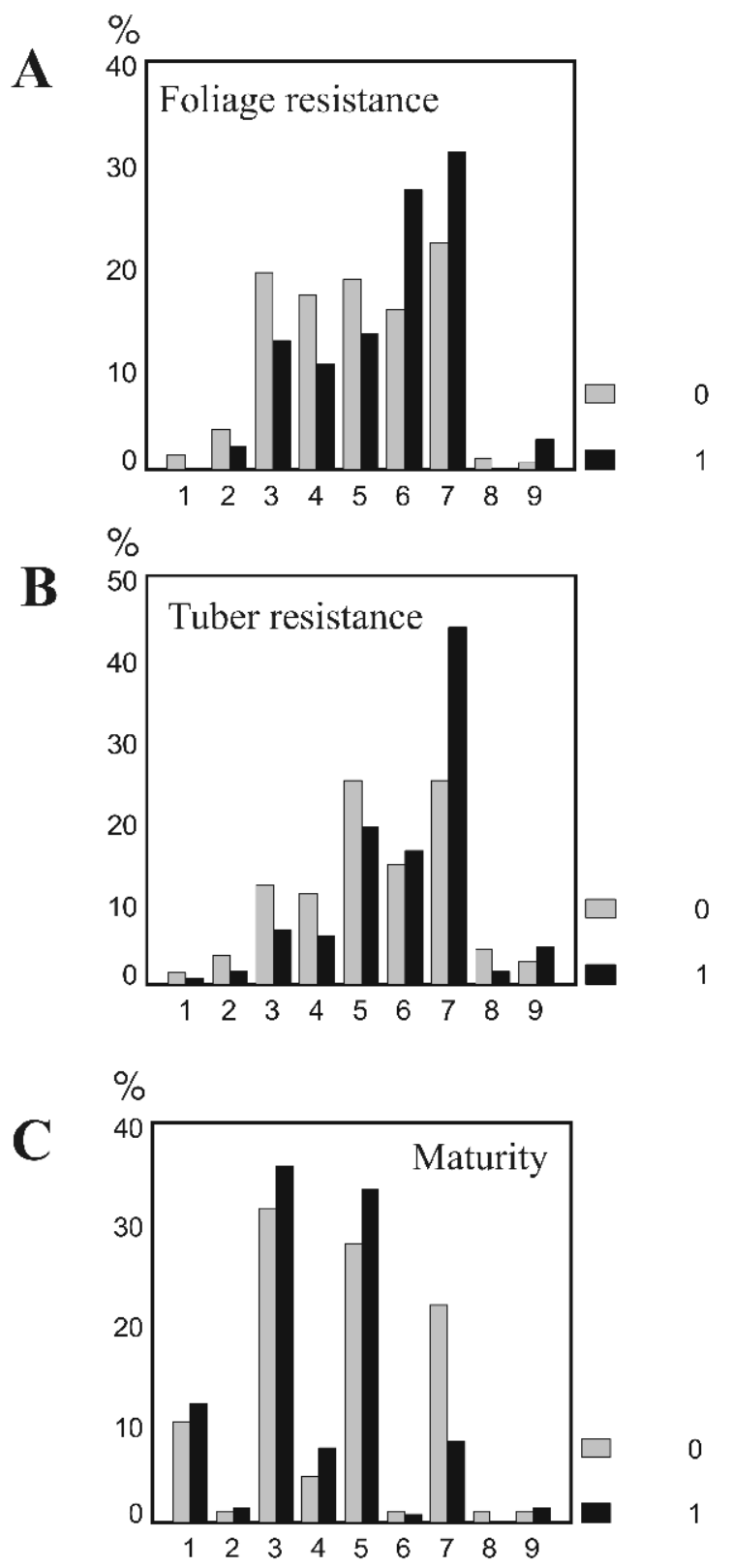

Figure 3. Frequency distribution (in percent) of cultivars having (black bars) or not having (grey bars) the $\mathrm{R} 1_{1400}$ fragment, over scores from 1 to 9 for late blight resistance of foliage (A) and tubers (B), and for maturity type (C). Score $1=$ highly susceptible, very late maturing. Score $9=$ highly resistant, very early maturing.

accession of S. stoloniferum (Figure 4). The fragment $\mathrm{R} 1_{1800}$ was absent in all species tested (data not shown). The combination of both $\operatorname{Cos} \mathrm{A}_{210}$ and $\mathrm{R} 1_{1400}$ was exclusively found in accessions of $S$. demissum. BA47f2 650 was found in one accession of S. demis- sum and in few other species accessions (Figure 4). In Solanum species other than S. demissum, marker BA47f2 generally produced several weak PCR fragments of variable size (data not shown). GP179 ${ }_{570}$ was absent in the Solanum species tested. Instead, all S. demissum accessions and some accession of other Solanum species had a smaller fragment of approx. 550 base pairs (Figure 4). These results indicate that amplicons $\mathrm{R} 1_{1400}$ and $\operatorname{Cos} \mathrm{A}_{210}$, possibly also amplicon $\mathrm{BA} 47 \mathrm{f} 2_{650}$, which were associated with resistance to late blight and maturity result from a genome fragment that has been introgressed into potato cultivars from $S$. demissum.

\section{Discussion}

Analysis of genetic linkage is based on measuring the frequency of recombination between pairs of loci in a single meiotic generation. Alleles that are physically linked in the parents (parental haplotypes) are transmitted together to the offspring except when recombination separates the two alleles. With each subsequent generation, the common transmission of coupled alleles is reduced in proportion to the recombination fraction until linkage equilibrium is reached, that is, recombinant and non-recombinant haplotypes are equally distributed in a population of individuals of common descent. In the case of very tight linkage between two loci, however, linkage disequilibrium can persist in a population over generations due to very low frequencies of recombination. When linkage disequilibrium exists between a molecular marker and an unknown locus controlling a phenotype of interest, specific haplotypes or marker alleles may be associated with phenotypic values measured in populations of individuals related by descent. To detect association between a DNA marker and an unknown factor controlling a quantitative character, the marker must be physically tightly linked, whereas detection of linkage is possible over relatively large distances between pairs of loci (Lander and Schork 1994).

The fact that marker-trait associations were detectable in the experiment described in this paper is remarkable because several aspects of the genetic material and the phenotypic evaluation data used were rather unfavorable for having success in the association test. The cultivar collection was heterogeneous in terms of place and time of origin. Based on breeding history (Ross 1986) and pedigree information (Swiezynski et al. 1997; Angeli et al. 2000) it 


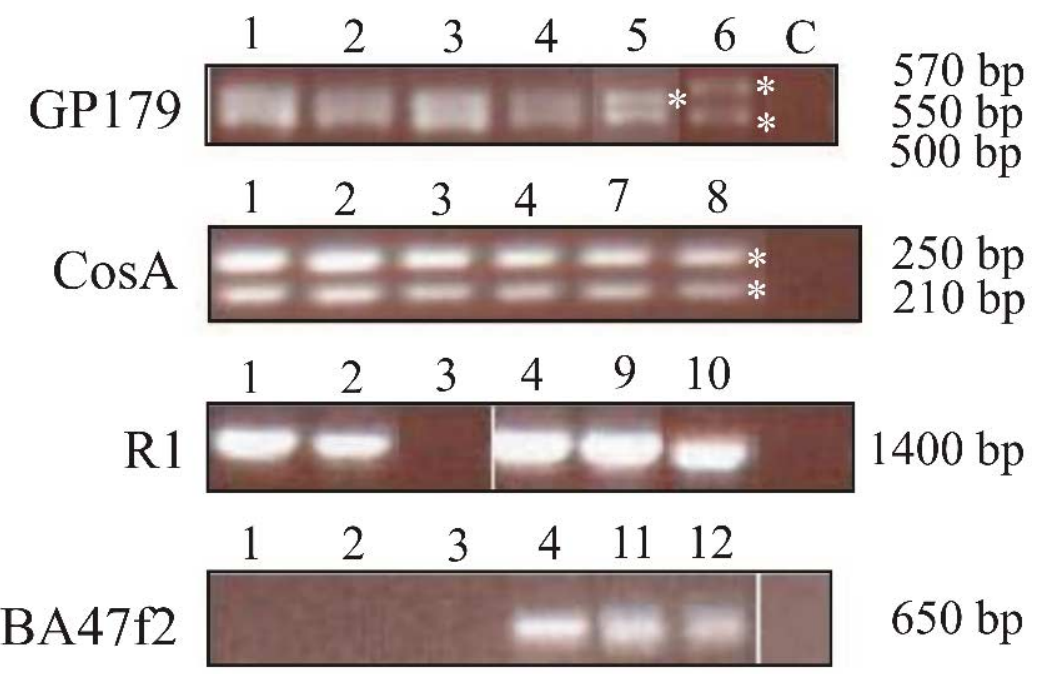

Figure 4. PCR products obtained with GP179, CosA, R1 and BA47f2 specific primers in accessions of S. demissum (lanes 1: BRGC010022, lanes 2: GLKS218, lanes 3: GLKS256, lanes 4: GLKS325), S. alandiae (lane 5: BGRC018521), S. microdontum (lane 7: BGRC024644), S. stoloniferum (lane 9: BRGC007229) and S. canasense (lane 11: BGRC008110). For comparison, varieties having fragments GP179 ${ }_{570}$, $\mathrm{CosaA}_{210}, \mathrm{R}_{1400}$ and $\mathrm{BA} 47 \mathrm{f}_{650}$ are shown in lanes $6,8,10$ and $12 . \mathrm{C}=$ water control.

also contained introgressions from various other Solanum species. Moreover, the phenotypic evaluation data originated from different countries using non-uniform evaluation standards (Swiezynski et al. 2001). Scores for late blight resistance are most likely based also on infections with different isolates of $P$. infestans. On the other hand, the pedigree structure of the cultivars indicated that few meiotic generations separate the individual genotypes from each other, therefore favoring the persistence of linkage disequilibrium and increasing the chance of detecting association.

The single marker haplotype constituted by fragments $\operatorname{Cos} \mathrm{A}_{210}, \mathrm{R} 1_{1400}$ and $\mathrm{BA} 47 \mathrm{f} 2_{650}$ associated with increased late blight resistance and later plant maturity was exclusively found in accessions of Solanum demissum, the wild species used since 1908 for introgressing genes for resistance to late blight (Ross 1986). This suggests that the observed markertrait association resulted from a possibly single introgression of $S$. demissum that contained the major resistance gene $R 1$. As fragment GP179 ${ }_{570}$ was not traceable to $S$. demissum or any other of the Solanum species tested, the border of the introgressed segment lays between the marker loci CosA and GP179. The marker-trait association shows that genes present in this introgressed genome segment still contribute to quantitative resistance to late blight, long after the $R I$ gene has been defeated by new virulent $P$. infestans isolates. Genes present in this segment also influence plant maturity under long day conditions.

The extent of linkage disequilibrium over genetic and physical distance was estimated by testing for association four markers that are located within $1 \mathrm{cM}$ genetic distance on potato chromosome V. Three markers, BA47f2, CosA and the $R 1$ resistance gene, that were associated with late blight resistance, are linked within $0.3 \mathrm{cM}$, whereas the GP179 marker that failed in the association test and was also outside of the introgressed $S$. demissum genome segment, is genetically separated from those three markers by 0.6 to $0.9 \mathrm{cM}$. This genetic distance was sufficient to reach linkage equilibrium between GP179 and the genes causal for the QTL effects. The observed genetic distance of $0.3 \mathrm{cM}$ sufficient for persistence of linkage disequilibrium in potato is in good agreement with the finding of Kraft et al. (2000) that high linkage disequilibrium between pairs of AFLP markers in sugar beet was observed with map distances of less than $0.2 \mathrm{cM}$. The genetic distance sufficient to reach linkage equilibrium in the potato cultivar collection was similar to the distance of $1 \mathrm{cM}$ between the maize Dwarf8 locus, that was associated with QTL for flowering time and the teosinte branched 1 locus that was not associated with QTL for flowering time (Thornsburry et al. 2001). The physical distance covered by the three associated markers is currently not known as the physical map is not complete for the 
whole region. The minimum size of the region is 300 $\mathrm{kb}$ as estimated from the length of the physical map constructed between two of the markers, BA47f2 and the $R l$ resistance locus (Ballvora et al. 2002). Linkage disequilibrium in this region ranges over a considerable physical distance, therefore, indicating a limited number of meioses separating the individual genotypes from each other. This is corroborated by the pedigree information available for part of the cultivar collection.

A second, weak association was detected between marker GP76 and maturity and resistance to late blight on potato chromosome VI. This suggests that association mapping is applicable also to other regions of the potato genome. The genetic and physical distance between a marker and the genes controlling a quantitative trait that is required for detecting association may vary greatly, however, for different regions of the potato genome.

The fact that CosA and markers for the $R I$ gene were associated with late blight resistance and maturity type whereas GP179 was not associated, makes possible to locate more precisely than QTL mapping (Leonards-Schippers et al. 1994; Oberhagemann et al. 1999) the genes that control a major portion of late blight resistance and plant maturity. These genes are located at or physically close to the $R 1$ locus. It has been suggested, based on the observed linkage between $R I$ and QTL for late blight resistance on potato chromosome V (Leonards-Schippers et al. 1994) that the $R 1$ gene and the genes for quantitative resistance are allelic variants or, alternatively, physically tightly linked members of the same gene family. Similarly, the phenotypic correlation between plant maturity and field resistance to late blight and the linkage between QTL for both traits suggested that plant maturity and late blight resistance are pleiotropic effects of the same gene(s) or closely linked genes (Oberhagemann et al. 1999; Collins et al. 1999). Association mapping delimited now the genomic region containing these genes to a physical size that is amenable to genomic sequencing as a first step towards the identification of candidate genes and evaluation of the above hypotheses at the molecular level.

The markers associated with resistance to late blight and plant maturity are the first ones that are diagnostic for quantitative agronomic characters in such a large germplasm pool. Presence of specific PCR fragments indicates, on average, higher or lower resistance to late blight and later plant maturity. For potato variety breeding, most desirable is a combina- tion of high late blight resistance with early plant maturity. The markers associated with both traits can be used to screen parental clones, to select new cross combinations and to assist in the selection of progeny that is, on average, more resistant or earlier maturing. Phenotypic selection or additional markers tagging other QTL for late blight resistance in the potato genome may then be used to identify in the group of more resistant plants earlier maturing genotypes or, vice versa, in the group of earlier maturing plants genotypes with higher levels of resistance to late blight.

\section{Acknowledgement}

This work was carried out in the department of yield physiology and plant breeding of the MPI for plant breeding research, headed by Francesco Salamini.

\section{References}

Angeli M., Klewsaat M., Vandrey M., Schüler K. 2000. Kulturkartoffelsortiment/Collection of Potato Varieties. 52 pp., Wilde und kultivierte Kartoffelarten aus Mittel- und Südamerika/wild and cultivated potato species from Central and South America, 123 pp. Inventory for 2000, IPK-Genbank Außenstelle Groß Lüsewitz.

Ballvora A., Ercolano M.R., Weiß J., Meksem K., Bormann C., Oberhagemann P., Salamini F., Gebhardt C. 2002. The R1 gene for potato resistance to late blight (Phytophthora infestans) belongs to the leucine zipper/NBS/LRR class of plant resistance genes. The Plant Journal 30: 361-371.

Collins A., Milbourne D., Ramsay L., Meyer R., Chatot-Balandras C., Oberhagemann P., De Jong W., Gebhardt C., Bonnel E., Waugh R. 1999. QTL for field resistance to late blight in potato are strongly correlated with earliness and vigour. Mol Breeding 5: 387-398.

Debener T., Salamini F., Gebhardt C. 1990. Phylogeny of wild and cultivated Solanum species based on nuclear restriction fragment length polymorphisms (RFLPs). Theor Appl Genet 79: 360-368.

Gebhardt C., Valkonen J.P.T. 2001. Organization of genes controlling disease resistance in the potato genome. Annu Rev Phytopathol 39: 79-102.

Hanson W.D. 1959. The breakup of initial linkage blocks under selected mating systems. Genetics 44: 857-868.

Kamoun S. 2001. Nonhost resistance to Phytophthora: novel prospects for a classical problem. Curr. Opin. Plant Biol. 4: 295-300.

Kraft T., Hansen M., Nilsson N.-O. 2000. Linkage disequilibrium and fingerprinting in sugar beet. Theor. Appl. Genet. 101: 323326.

Lander E.S., Schork N.J. 1994. Genetic dissection of complex traits. Science 265: 2037-2048.

Leonards-Schippers C., Gieffers W., Salamini F., Gebhardt C. 1992. The R1 gene conferring race-specific resistance to 
Phytophthora infestans in potato is located on potato chromosome V. Mol. Gen. Genet. 233: 278-283.

Leonards-Schippers C., Gieffers W., Schäfer-Pregl R., Ritter E., Knapp S.J., Salamini F., Gebhardt C. 1994. Quantitative resistance to Phytophthora infestans in potato: a case study for QTL mapping in an allogamous plant species. Genetics 137: 67-77.

Meksem K., Leister D., Peleman J., Zabeau M., Salamini F., Gebhardt C. 1995. A high-resolution map of the vicinity of the Rl locus on chromosome $\mathrm{V}$ of potato based on RFLP and AFLP markers. Mol. Gen. Genet. 249: 74-81.

Oberhagemann P., Chatot-Balandras C., Bonnel E., Schäfer-Pregl R., Wegener D., Palomino C., Salamini F., Gebhardt C. 1999. A genetic analysis of quantitative resistance to late blight in potato: Towards marker assisted selection. Mol. Breeding 5: 399415.

Risch N.J. 2000. Searching for genetic determinants in the new millennium. Nature 405: 847-856.

Ross H. 1986. Potato Breeding - Problems and Perspectives. J. Plant Breed. Suppl. 13.

Salamini F., Özkan H., Brandolini A., Schäfer-Pregl R., Martin W. 2002. Genetics and geography of wild cereal domestication in the near east. Nature Reviews Genetics 3: 429-441.
Schafer A.J., Hawkins J.R. 1998. DNA variation and the future of human genetics. Nature Biotechnology 16: 33-39.

Steineck O. 1956. Tageslänge und Knollenbildung bei Kultursorten der Kartoffel. Z. für Pflanzenzüchtung 36: 197-213.

Swiezynski K.M., Chrzanowska M., Domanski L., Zimnoch-Guzowska E. 2001. Comparison of resistance evaluation in potato variety assessment. Pot. Res. 44: 25-31.

Swiezynski K.M., Haynes K.G., Hutten R.C.B., Sieczka M.T., Watts P., Zimnoch-Guzowska E. 1997. Pedigree of European and North-American potato varieties. Plant Breeding and Seed Science 41, Supplement no. 1.

Thornsburry J.M., Goodman M.M., Doebley J., Kresovich S., Nielsen D., Buckler IV E.S. 2001. Dwarf8 polymorphisms associate with variation in flowering time. Nature Genetics 28: 286289.

Visker M.H.P.W., Keizer L.C.P., Van Eck H.J., Jacobsen E., Colon L.T., Struik P.C. 2003. Can the QTL for late blight resistance on potato chromosome 5 be attributed to foliage maturity type? Theor. Appl. Genet. 106: 317-325.

Xiong M.I., Guo S.W. 1997. Fine-scale mapping of quantitative trait loci using historical recombinations. Genetics 145: 1201-1218. 